\title{
Conditional Targeting in the Kidney
}

\author{
Fiona $\mathrm{Wu}$ \\ Department of Clinical Sciences, Bristol University, Bristol, UK
}

\section{Key Words}

Kidney-specific targeting $\cdot$ Inducible targeting $\cdot$ Cre/loxP

\section{Abstract}

Conditional gene targeting utilising the Cre/loxP system, which allows spatial and temporal control of gene expression, has been increasingly used to study gene function in vivo. The ability to limit gene disruption to a particular cell type and/or to control the timing of gene targeting overcomes some of the limitations associated with conventional targeting and total knockout of a gene, namely, potential embryonic lethality and complicated phenotype affecting multiple tissues. Although the application of this approach to the kidney is relatively recent, it has already proven to enhance our ability to study the developmental, physiological, and pathological processes in the kidney: dissecting the roles of several proteins in complex homeostatic systems, uncovering novel actions of proteins, and establishing models of kidney diseases. As the number of kidney-specific Cre mouse strains increases, this strategy will allow increasingly specific and complicated biological questions in the kidney to be addressed.

Copyright $\odot 2007$ S. Karger AG, Basel
\end{abstract}

\section{Introduction}

The similarities in the genetic and cellular functions between mouse and man as well as our ability to manipulate the murine genome by molecular means have led to the widespread use of the mouse as an experimental model to study human disease and development. Gene targeting in mouse embryonic stem (ES) cells by homologous recombination, a process whereby a fragment of exogenously introduced DNA containing the desired mutation locates and recombines with the endogenous homologous sequence, allows direct alterations to be introduced into the mouse genome at a predetermined site [1]. The targeted ES cells are then injected into blastocysts to produce chimeric mice, which are bred to produce animals that are homozygous or heterozygous for the mutated gene. There are two particular limitations with conventional targeting: (1) because the mutation is transmitted through the germ-line, animals derived from these ES cells are affected by gene dysfunction throughout ontogenesis and early lethality may result if the protein is essential for development, thus precluding analysis of the gene function later in life, and (2) inactivation of a widely expressed gene may result in a complex phenotype affecting multiple tissues, thereby making the interpretation of its functional significance in a particular tissue difficult. Conditional targeting, which allows spatial and

Fiona $\mathrm{Wu}$

Department of Clinical Sciences, Medical School Unit

Southmead Hospital

Westbury-on-Trym BS10 5NB (UK)

Tel. +44 117959 5283, Fax +44 117970 1212, E-Mail fiona.wu@bristol.ac.uk 
temporal control of gene expression, overcomes some of these problems and has enhanced our ability to study the developmental, physiological, and pathological processes in the kidney.

\section{Tissue-Specific Targeting}

The most widely used strategy to limit gene targeting to specific tissue or cell types utilises the Cre/loxP system. The Cre recombinase is a bacteriophage P1 enzyme that mediates DNA recombination between two appropriately configured 34-basepair recognition sequences $(\operatorname{lox} P)$, which results in deletion of the intervening DNA sequence. In this approach (fig. 1), one transgenic mouse line, which expresses the Cre recombinase under the control of a tissue-specific promoter, is crossed with a second mouse line carrying alleles in which two loxP sites flank an essential part of the gene to be studied ('floxed' gene). In the offspring that inherits both the Cre transgene and the floxed alleles, Cre-mediated DNA deletion eliminates functional protein expression in cells expressing the Cre recombinase as determined by the promoter while leaving the expression of the protein in other cells intact. The success of kidney-specific targeting is dependent on the availability of different Cre transgenic lines and the efficiency of the lineage-specific DNA excision. There are a number of kidney-specific Cre mouse strains currently available (see [2] and references contained therein), which potentially allow for gene targeting in the podocytes, proximal tubule, thick ascending limbs, juxtaglomerular cells and principle cells of the collecting duct (CD). This review discusses the genes that have been successfully targeted to date using the kidney-specific Cre/loxP strategy (table 1) to illustrate the value of this technology in studying renal biology and disease.

\section{Regulation of Fluid Balance and Systemic Blood \\ Pressure}

The endothelin (ET) system has been implicated in the regulation of systemic blood pressure through multiple mechanisms, and conditional targeting of components of this complex system has facilitated the process of dissecting their relative contributions and mechanisms of action $[3,4]$. Inactivation of the peptide, ET- 1 , in the CDs of mice leads to hypertension, impaired ability to excrete sodium and water loads, and enhanced vasopressin responsiveness [3]. In contrast, disruption of the ET-A receptor in the $\mathrm{CD}$ decreases vasopressin sensitivity but has no effect

Conditional Targeting in the Kidney on systemic blood pressure or salt balance [4]. Via the inhibitory effect of ET-1 on vasopressin action, these studies suggest that CD-derived ET-1 is a regulator of systemic blood pressure with significant natriuretic and diuretic effects in the distal nephron, and ET-A may serve as a counter-regulatory mechanism to dampen the diuretic effect of ET-1.

The apical plasma membrane water channel, aquaporin-2 (AQP2), present in the connecting tubules (CNTs) and in the $\mathrm{CD}$ principal cells, is the chief target for regulating the water permeability of these segments by vasopressin. Mice lacking AQP2 in both segments die postnatally with severely impaired postnatal kidney development, whereas those mice lacking AQP2 expression in only the CD cells survive to adulthood but show marked polyuria and severe urinary-concentrating defects [5]. These results demonstrate that AQP2 in CNTs is sufficient for postnatal survival but cannot compensate for the essential role of AQP2 in the CDs in the regulation of body water balance. Interestingly, in contrast to the importance of $\mathrm{CD}$ function in regulating water balance [5], specific deletion of the apical epithelial sodium channel $(\mathrm{ENaC})$ in the cortical CDs of mice does not cause significant abnormalities in sodium or potassium balance, suggesting that only the CNT and late distal convoluted tubule are quantitatively important in maintaining sodium balance [6].

$\mathrm{CD}$-specific inactivation of the nuclear receptor, peroxisome proliferator-activated receptor- $\gamma$ (PPAR $\gamma)$ in mice provided evidence that $\mathrm{ENaC}-\gamma$ subunit transcription and $\mathrm{ENaC}$-mediated sodium reabsorption is PPAR $\gamma$ sensitive [7]. It is estimated that $80-90 \%$ of the fluid retention associated with the use of the PPAR $\gamma$ agonist, thiazolidinedione (TZD), in man is due to enhanced $\mathrm{ENaC}$-mediated fluid reabsorption in the distal nephron [7]. These experiments thus revealed a novel action of PPAR $\gamma$ in the distal nephron and identified a target to counteract TZD-induced oedema.

\section{Vitamin and Mineral Homeostasis}

The endocytic receptor in the proximal tubule (PT), megalin, is important for the reabsorption of macromolecules filtered by the glomerulus, including several vitamin-carrier proteins such as the retinol- and vitamin Dbinding proteins. The conventional megalin-knockout mice die perinatally from defective forebrain development, whereas mice with a kidney-specific megalin defect develop normally but exhibit multiple defects in vitamin and mineral handling [8-11]. Megalin deficiency in the PT is associated with low molecular weight pro- 


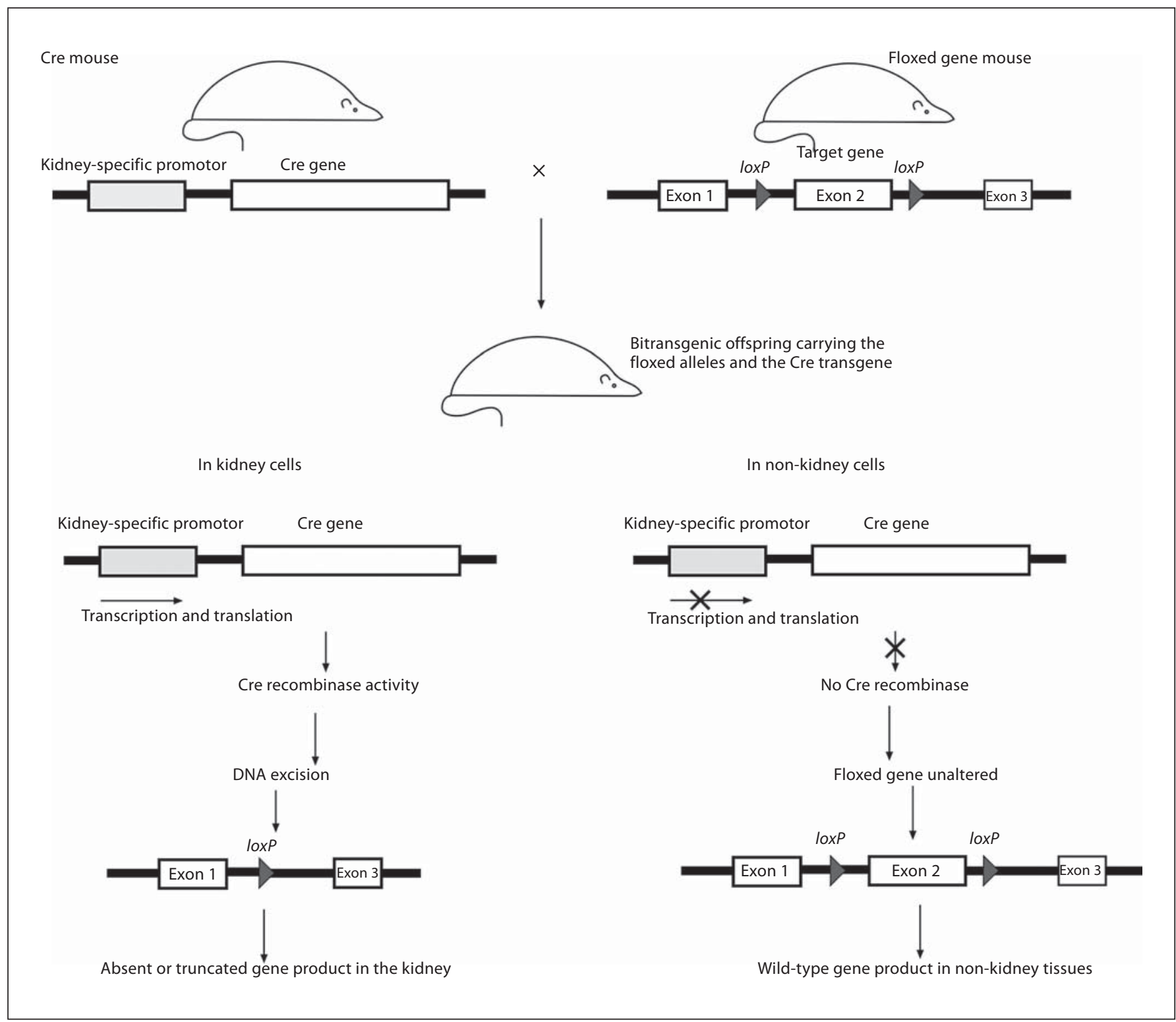

Fig. 1. Kidney-specific gene targeting with the Cre/loxP system. Two separate transgenic mouse strains are required to disrupt a gene of interest in a tissue- or cell-specific manner. One strain expresses the Cre recombinase under the control of a kidney-specific promoter and is generated by transgene injection of fertilised oocytes; the other carries two loxP sites flanking a segment of the gene to be studied ('floxed') and is generated by homologous recombination in embryonic stem cells. Generally, the loxP sites are located in the introns and flank an essential exon(s) of the gene such that the gene expression is unaffected. The two strains are crossed to produce offspring that carry the Cre transgene and are homozygous for the floxed gene (for simplicity, only one of the two floxed alleles is shown). In these offspring, Cre-mediated DNA deletion in the kidney cells results in the disruption of the target gene exclusively in the renal tissue. teinuria, increased urinary loss of vitamin D-binding protein and 25-hydroxyvitamin $\mathrm{D}$, systemic hypovitaminosis, hypocalcaemia, and osteomalacia [9]. There is also increased urinary loss of retinol, which is compensated by accelerated mobilisation of hepatic stores to maintain normal plasma retinol levels [10]. Renal phosphate reabsorption, $>70 \%$ of which is mediated by the type-II sodium phosphate co-transporter ( NaPi-IIa) located in the PT brush borders, is also affected [11]. Megalin deficiency in the PT induces ultrastructural altera- 
Table 1. Kidney-specific gene targeting

\begin{tabular}{|c|c|c|c|c|c|c|}
\hline Cre mouse ${ }^{1}$ & Promoter $^{2}$ & Renal expression ${ }^{3}$ & $\begin{array}{l}\text { Extrarenal } \\
\text { expression }^{3}\end{array}$ & & Targeted gene inactivation & Ref. \\
\hline AQP2-CreTag & AQP2 & $\mathrm{CD}$ (principal cells) & $\begin{array}{l}\text { Testis, vas } \\
\text { deferens }\end{array}$ & & $\begin{array}{l}\text { ET-1: Hypertension, salt retention, } \uparrow \text { vasopressin sensitivity } \\
\text { ET-A Receptor: Normotension, } \downarrow \text { vasopressin } \\
\text { sensitivity } \\
\text { PPAR } \gamma: \downarrow_{\text {renal sodium avidity, resistant to TZD-induced }} \\
\text { oedema }\end{array}$ & $\begin{array}{l}3 \\
4 \\
7\end{array}$ \\
\hline HoxB7-Cre & Hox-B7 & $\mathrm{CD}$, ureter & $\begin{array}{l}\text { Developing } \\
\text { GUT, spinal } \\
\text { cord, dorsal root } \\
\text { ganglia }\end{array}$ & & $\begin{array}{l}\text { AQP2: Severe urinary concentrating defect } \\
\alpha \text {-ENaC: Normal sodium and potassium balance } \\
\text { Smad4: Normal embryonic CD development; } \\
\text { normal phenotype up to age } 6 \text { weeks } \\
\text { Shh: Hypoplasia, hydronephrosis, and hydroureter }\end{array}$ & $\begin{array}{r}5 \\
6 \\
18 \\
19\end{array}$ \\
\hline ApoE-Cre & Human apoE & PT, DT & Not specified & & $\begin{array}{l}\text { Megalin: Hypovitaminosis, hypocalaemia, osteomalacia, } \\
\uparrow \text { urinary retinol excretion, } \downarrow \text { phosphaturia }\end{array}$ & $9-11$ \\
\hline Ksp1.3/Cre & Ksp-cadherin & $\begin{array}{l}\text { Predominantly CD, } \\
\text { TAL }\end{array}$ & Developing GUT & & $\begin{array}{l}\text { KIF3A: Polycystic phenotype } \\
\text { HNF1 } \beta \text { : Polycystic phenotype } \\
\text { APC: Polycystic phenotype, neonatal lethality, } \\
\text { and neoplasm }\end{array}$ & $\begin{array}{r}12 \\
3 \\
16\end{array}$ \\
\hline MMTV-Cre & MMTV LTR & Not specified & Secretory organs & & PKD1: Renal and hepatic cysts & 14 \\
\hline PEPCK-Cre & PEPCK & $\mathrm{PT}$ & Hepatocytes & & $\begin{array}{l}\text { VHL: Renal cysts, liver haemangiomas, } \\
\text { polycythaemia }\end{array}$ & 15 \\
\hline AhCre & Cyp1A1 & CD, Glom & Not specified & & APC: Renal carcinoma & 17 \\
\hline $\mathrm{Bmp} 7^{\mathrm{cre} /+}$ & BMP-7 & $\mathrm{CD}$, mesenchyme & Developing GUT & & $\begin{array}{l}\text { Smad4: Defective mesenchymal induction, and } \\
\text { organisation }\end{array}$ & 18 \\
\hline Neph-Cre & Nephrin & Glom (podocytes) & Brain (low) & & VEGF-A: Defective glomerular filtration barrier & 20 \\
\hline $\begin{array}{l}\text { Inducible } \\
\text { Cre mouse }\end{array}$ & Promoter & Renal expression & $\begin{array}{l}\text { Extrarenal } \\
\text { expression }\end{array}$ & Inducer & Targeted gene & Ref. \\
\hline Cre-ER ${ }^{\mathrm{TM}}$ & pCAGGS & Not specified & Ubiquitous & Tamoxifen & $\begin{array}{l}\text { Inactivation } \\
\text { AQP2: Nephrogenic diabetes insipidus }\end{array}$ & 21 \\
\hline$\beta \mathrm{MCM}_{86}$ & pCAGGS & Glom (podocytes) & $\begin{array}{l}\text { Sk and card } \\
\text { muscle }\end{array}$ & Tamoxifen & $\begin{array}{l}\text { Activation } \\
\text { PAX2: Glomerular sclerosis, fibrosis, and } \\
\text { proteinura }\end{array}$ & 22 \\
\hline
\end{tabular}

Symbols and abbreviations: apoE $=$ apolipoprotein E; APC $=$ adenomatous polyposis coli tumour suppressor; $\mathrm{AQP} 2$ = aquaporin-2 water channel; BMP-7 = bone morphogenetic protein7; ETA = endothelin- $\mathrm{A}$; ET-1 = endothelin-1; $\alpha$-ENaC $=$ epithelial $\mathrm{Na}^{+}$channel $\alpha$-subunit; pCAGGS $=$ CMV-enhanced chicken $\beta$-actin; CYP1A1 $=$ cytochrome P4501A1; HNF1 $\beta$ = hepatic nuclear factor $1 \beta$; Hox-B = subclass of the Homeobox gene superfamily; KIF3A = kinesin-II subunit; MMTV LTR = mouse mammary tumour virus long terminal repeat; PAX2 = paired box gene 2 ; PDK1 = polycystic kidney disease $1 ; \mathrm{PEPCK}=$ phosphoenolpyruvate carboxykinase; PPAR $\gamma=$ peroxisome proliferator-activated receptor subtype $\gamma ; \operatorname{Smad} 4=$ mothers against decapentaplegic homolog 4 (Drosoph- ila); Shh = sonic hedgehog; TZD = thiazolidinedione; VEGF-A = vascular endothelial growth factor $\mathrm{A} ; \mathrm{VHL}=$ von Hippel-Lindau tumour suppressor; $\downarrow=$ decreased; $\uparrow=$ increased; CD = collecting duct; card $=$ cardiac; $\mathrm{DT}=$ distal tubule; Glom = glomerulus; GUT = genitourinary tract; $\mathrm{PT}=$ proximal tubule; $\mathrm{TAL}=$ thick ascending loop of Henle; $\mathrm{Sk}=$ skeletal.

${ }^{1}$ References for the specific Cre mouse strains used in the targeting studies are contained in the articles cited.

${ }^{2}$ Promoters used to control the tissue-specific Cre expression in transgenic mice.

${ }^{3}$ Expression of Cre-recombinase in the kidney and other tissues. tions in the endocytic apparatus, resulting in enhanced brush border expression of NaPi-IIa and reduced urinary excretion of phosphate in the steady state. The internalisation of NaPi-IIa from the brush border membrane in response to parathyroid hormone is also impaired in the absence of megalin.

\section{Renal Cystic Disease}

A number of mechanisms and genes have been implicated in renal cystogenesis [12-14]. Kidney-specific inactivation of the kinesin II subunit, KIF3A, results in animals with morphologically normal kidneys at birth that progressively develop multiple cysts and renal failure 
[12]. The cystic epithelial cells lack primary cilia and show altered cellular properties, suggesting a role for the kinesin II tubular motor protein complex in maintaining the normal structure and function of the renal epithelium. Specific inactivation of hepatic nuclear factor- $1 \beta$ in the murine renal epithelium also results in the development of renal cysts [13]. This is accompanied by transcriptional defects and downregulation of protein expression of several cystic disease genes in the cystic epithelium, indicating that dysregulation of the transcription network plays an important role in cystogenesis [13]. Somatic inactivation of the murine homolog of $P K D 1$, mutations of which account for $85 \%$ of the patients with autosomal dominant polycystic kidney disease, results in the progressive development of renal and hepatic cysts in the mature animal [14]. This conditional mouse model should thus be invaluable for studying the biological role of polycystin-1, the protein encoded by $P K D 1$, and the pathogenesis of autosomal dominant polycystic kidney disease [14].

\section{Renal Neoplasia}

Mutations in the von Hippel-Lindau (VHL) tumour suppressor gene are found in both hereditary and sporadic clear cell renal cell carcinoma (CCRCC), with the former being part of the VHL disease, which is characterised by the development of tumours in multiple organs [15]. Mice with inactivation of the VHL gene in the kidney develop renal cysts, a pathological finding associated with both sporadic and hereditary CCRCC. Furthermore, the renal cysts in these mutant mice share morphological and molecular features with those found in VHL patients [15]. However, these mice do not develop CCRCC, suggesting that while the disruption of the VHL tumour suppressor is critical in renal carcinogenesis, other genetic events are required for the progression of the cysts to carcinoma. Inactivation of the adenomatous polyposis coli (APC) tumour suppressor gene in the murine renal epithelium demonstrated that the loss of the protein and the associated dysregulation of the $\beta$-catenin signalling pathway predispose to developing renal carcinoma [16, 17]. In one study, the loss of APC tumour suppressor is associated with early onset polycystic kidney disease and neonatal death in most animals, with the rare surviving individuals developing large, multilayered cysts with features of adenoma or carcinoma in situ [16]. In a separate study, the mutant mice develop multiple dysplastic foci and renal carcinoma [17]. These phenotypic differences probably reflect differences in the two Cre recombinases targeting different cells within the kidney or the short- ened life span of the first mouse model precluding progression to carcinoma.

\section{Renal Organogenesis}

Normal kidney development depends on the reciprocal interactions between the ureteric bud and the metanephric mesenchyme in the developing genitourinary tract. By selectively disrupting the expression of transcription factor Smad4 in these two cell populations, it was demonstrated that $\mathrm{CD}$ development is independent of Smad4, which is a key component of the transforming growth factor- $\beta$ (TGF- $\beta$ ) signalling pathway [18]. However, the absence of Smad4 in the mesenchyme leads to defective organisation and induction of the nephrogenic mesenchyme, indicating the importance of the TGF- $\beta$ signalling pathway in early kidney development [18]. Inactivation of the signalling protein, Sonic hedgehog (Shh), in the murine $\mathrm{CD}$ epithelium results in renal hypoplasia, hydronephrosis, and hydroureter [19]. In vivo and in vitro analyses showed that Shh acts as a paracrine factor to promote mesenchymal cell proliferation, regulate smooth muscle progenitor cell differentiation, and set the pattern of mesenchymal differentiation [19]. Specific inactivation of the vascular endothelial growth factor-A (VEGF-A) in podocytes revealed that heterozygosity for VEGF-A results in early onset proteinuria and a renal lesion similar to that seen in preeclampsia [20]. Homozygous VEGF-A deletion in the podocytes leads to a failure of glomerular filtration barrier formation and perinatal mortality [20]. These results indicate that tight regulation of VEGF signalling between the podocytes and glomerular endothelium is required for formation and maintenance of the glomerular filtration barrier.

\section{Inducible Targeting}

Inducible gene targeting, which allows control of the onset and reversibility of the genetic defect, have several theoretical additional advantages: (1) by timing the gene targeting, potential adverse effects of defective gene function during earlier life can be avoided and also provides a more precise model of disease which develops in adult life; (2) the phenotypes, before and after the gene targeting, act as internal controls and eliminate the need for generating appropriate wild-type controls, which can be time consuming and costly, and (3) reversible gene targeting may demonstrate that the phenotype is clearly associated with the mutated gene, as reversion back to a functional gene should reverse the observed effects. 
In the kidney, inducible gene disruption has been developed using ligand-regulated Cre recombinases. Most commonly, the chimeric protein consists of a Cre recombinase fused with a mutant oestrogen receptor ligandbinding domain and its expression is under the control of a kidney-specific promoter [2]. In the absence of the ligand, the Cre is expressed but remains inactive in the cytoplasm, where it is bound to heat shock proteins. Binding of the ligand to the Cre displaces the heat shock proteins and the Cre translocates into the nucleus, where it mediates loxP-flanked DNA excision. The successful application of this system in the kidney has been limited by the efficiency of the Cre-mediated excision. Recently, the first adult mouse model of nephrogenic diabetes insipidus was generated by tamoxifen-induced Cre-mediated $\mathrm{AQP} 2$ gene deletion (table 1). In the absence of tamoxifen, the adult Cre-AQP2-loxP mice are phenotypically normal; following tamoxifen treatment, there is a $>95 \%$ reduction in the AQP2 protein level in the kidney and the mice develop severe polyuria, hypotonic urine, and unresponsiveness to water deprivation [21].

In addition to ablating gene function, conditional targeting can also be used to activate gene function. In this case, Cre-mediated recombination removes a functional barrier to the production of an active gene product, thereby switching on gene expression [22]. Using this ap- proach, a mouse model has been developed which allows inducible activation of Pax2 within the podocytes [22]. Following activation of $\operatorname{Pax} 2$, healthy adult mice develop renal disease and proteinuria associated with inhibition of the podocyte key regulator molecule Wt1 and a dramatic reduction in nephrin expression in the glomerulus. This suggests that the ectopic expression of PAX2 in the podocytes plays an important role in the development of glomerular disease [22].

\section{Conclusion}

Within a relatively short space of time, kidney-specific gene targeting utilising the Cre/loxP system has facilitated studies to dissect out the roles of individual components of several of the complex homeostatic systems operating in the kidney, to uncover novel actions of proteins, and provide important new insights into renal development, physiology, and pathophysiology that have not been possible with more traditional methods. As the number of mouse lines with specific and efficient inducible Cre activity in the different nephron segments and cell types increases, this technology will allow us to ask increasingly more sophisticated and specific biological questions.

\section{References}

1 Capecchi MR: Altering the genome by homologous recombination. Science 1989;244: 1288-1292

-2 Lantinga-van Leeuwen IS, Leonhard WN, van de Wal A, Breuning MH, Verbeek S, de Heer E, Peters DJM: Transgenic mice expressing tamoxifen-inducible Cre for somatic gene modification in renal epithelial cells. Genesis 2006;44:225-232.

- 3 Ge Y, Ahn D, Stricklett PK, Hughes AK, Yanagisawa M, Verbalis JG, Kohan DE: Collecting duct-specific knockout of endothelin-1 alters vasopressin regulation of urine osmolality. Am J Physiol Renal Physiol 2005; 288:F912-F920.

4 Ge Y, Strickett PK, Hughes AK, Yanagisawa M, Kohan DE: Collecting duct-specific knockout of the endothelin A receptor alters renal vasopressin responsiveness, but not sodium excretion or blood pressure. Am J Physiol Renal Physiol 2005;289:F692-F698.

5 Rojek A, Füchtbauer E-M, Kwon T-H, Frokiaer J, Nielsen S: Severe urinary concentrating defect in renal collecting duct-selective AQP2 conditional-knockout mice. Proc Natl Acad Sci USA 2006;103:6307-6342.
6 Rubera I, Loffing J, Palmer LG, Frindt G, Fowler-Jaeger N, Sauter D, Carroll T, McMahon A, Hummler E, Rossier BC: Collecting duct-specific gene inactivation of alpha$\mathrm{ENaC}$ in the mouse kidney does not impair sodium and potassium balance. J Clin Invest 2003;112:554-565.

7 Guan Y, Hao C, Cha DR, Rao R, Lu W, Kohan DE, Magnuson MA, Redha R, Zhang Y, Breyer MD: Thiazolidinediones expand body fluid volume through PPARgamma stimulation of ENaC-mediated renal salt absorption. Nat Med 2005;11:861-866.

$\checkmark 8$ Willnow TE, Hilpert J, Armstrong S, Rohlmann A, Hammer RE, Burns DK, Herz J: Defective forebrain development in mice lacking gp330/megalin. Proc Natl Acad Sci USA 1996;93:8460-8464.

$\checkmark 9$ Leheste JR, Melsen F, Wellner M, Jansen P, Schlichting U, Renner-Müller I, Andreassen TT, Wolf E, Bachmann S, Nykjaer A, Willnow TE: Hypocalcemia and osteopathy in mice with kidney-specific megalin gene defect. FASEB J 2003;17:247-249.
10 Raila J, Willnow TE, Schweigert FJ: Megalinmediated reuptake of retinol in the kidneys of mice is essential for vitamin A homeostasis. J Nutr 2005; 135:2512-2516.

11 Bachmann S, Schlichting U, Geist B, Mutig K, Petsch T, Bacic D, Wagner CA, Kaissling B, Biber J, Murer H, Willnow TE: Kidneyspecific inactivation of the megalin gene impairs trafficking of renal inorganic sodium phosphate cotransporter (NaPi-IIa). J Am Soc Nephrol 2004;15:892-900.

12 Lin F, Hiesberger T, Cordes K, Sinclair AM, Goldstein LSB, Somlo S, Igarashi P: Kidney-specific inactivation of the KIF3A subunit of kinesin-II inhibits renal ciliogenesis and produces polycystic kidney disease. Proc Natl Acad Sci USA 2003;100:52865291.

13 Gresh L, Fischer E, Reimann A, Tanguy M, Garbay S, Shao X, Hiesberger T, Fiette L, Igarashi $\mathrm{P}$, Yaniv M, Pontoglio $\mathrm{M}$ : A transcriptional network in polycystic kidney disease. EMBO J 2004;23:1657-1668. 
14 Piontek KB, Huso DL, Grinberg A, Liu L, Bedja D, Zhao H, Gabrielson K, Qian F, Mei C, Westphal H, Germino GG: A functional floxed allele of $P k d 1$ that can be conditionally inactivated in vivo. J Am Soc Nephrol 2004;15:3035-3043.

15 Rankin EB, Tomaszewski JE, Haase VH: Renal cyst development in mice with conditional inactivation of the von Hippel-Lindau tumor suppressor. Cancer Res 2006;66: 2576-2583.

16 Qian CN, Knol J, Igarashi P, Lin F, Zylstra U, Teh BT, Williams BO: Cystic renal neoplasia following conditional inactivation of apc in mouse renal tubular epithelium. J Biol Chem 2005;280:3938-3945
Sansom OJ, Griffiths DFR, Reed KR, Winton DJ, Clarke AR: Apc deficiency predisposes to renal carcinoma in the mouse. Oncogene 2005;24:8205-8210.

18 Oxburgh L, Chu GC, Michael SK, Robertson EJ: TGF $\beta$ superfamily signals are required for morphogenesis of the kidney mesenchyme progenitor population. Development 2004;131:4593-4605.

19 Yu J, Carroll TJ, McMahon AP: Sonic hedgehog regulates proliferation and differentiation of mesenchymal cells in the mouse metanephric kidney. Development 2002; 129:5301-5312.
20 Eremina V, Sood M, Haigh J, Nagy A, Lajoie G, Ferrara N, Gerber H-P, Kikkawa Y, Miner JH, Quaggin SE: Glomerular-specific alterations of VEGF-A expression lead to distinct congenital and acquired renal diseases. J Clin Invest 2003;111:707-716.

21 Yang B, Zhao D, Qian L, Verkman AS: Mouse model of inducible nephrogenic diabetes insipidus produced by floxed aquaporin-2 gene deletion. Am J Physiol Renal Physiol 2006; 291:F465-F472.

22 Wagner K-D, Wagner N, Guo J-K, Elger M, Dallman MJ, Bugeon L, Schedl A: An inducible mouse model for PAX2-dependent glomerular disease: insights into a complex pathogenesis. Curr Biol 2006;16:793-800. 